\title{
A EDUCAÇÃO ANARQUISTA E A EDUCAÇÃO PÚBLICA ESTATAL BRASILEIRA: O ENCONTRO DE DOIS PARADIGMAS
}

\author{
Juliana Guedes dos Santos Marconi ${ }^{1}$ \\ julianaguedes_ufscar@yahoo.com.br
}

Prof. Dr. Luiz Bezerra Neto ${ }^{2}$ lbezerra@ufscar.com.br

\author{
Universidade Federal de São Carlos - UFSCar
}

\section{RESUMO:}

$\mathrm{O}$ presente trabalho procura refletir acerca de duas vertentes educacionais existentes no Brasil: a Educação Pública Estatal, que sempre se ministrou na história da educação brasileira, e as Escolas Libertárias baseadas no ideário anarquista, vigentes na década de 1920, com o objetivo de compreender o desenvolvimento das escolas anarquistas e apontar algumas semelhanças e diferenças em relação às escolas públicas estatais. Para tanto, foi analisada parte da literatura que trata da História do Brasil (principalmente a época em que se deu a imigração européia), da história da educação brasileira, dos princípios e ideais anarquistas e da educação libertária, com o objetivo de se traçar um panorama das principais iniciativas estatais de educação desde a Proclamação da República até o Plano Nacional de Educação (2000), além da discussão sobre os ideais e princípios do anarquismo visando compreender melhor a Educação Libertária. Por fim, pode-se concluir que, embora existam momentos em que as concepções analisadas se divergem e se convergem, a diferença fundamental entre a educação que vemos proferida pelas escolas públicas e as libertárias está na questão da representatividade e participação na gestão educacional.

Palavras-chaves: Educação Pública Estatal - Anarquismo - Educação Libertária.

\section{ANARCHIST EDUCATION AND BRAZILIAN STATE PUBLIC EDUCATION: THE MEETING OF TWO PARADIGMS}

\begin{abstract}
:
This paper aims at reflecting on two educational aspects existing in Brazil: the State Public Education that has been provided all along the Brazilian educational history, and the Libertarian Anarchist ideas, effective during the 1920s, with the aim of understanding the development of anarchist schools and pointing out some similarities and differences in relation to state public schools. To that end, it was considered part of the literature that deals with the History of Brazil (mainly the period of European immigration), the history of Brazilian education, and the principles and ideals of the libertarian anarchist education in order to draw a picture of the main state educational initiatives from the Proclamation of Republic to the National Plan of Education (2000), in addition to the discussion about the ideals and principles of anarchism with the purpose of better understanding the Libertarian Education. Thus, it is possible to conclude that although there are times when the concepts discussed show convergent and divergent ideas, the fundamental difference between the education provided by the public schools and the libertarian ones is the question of representation and participation in educational management.
\end{abstract}

Key-words: State Public Education - Anarchism - Libertarian Education 
Discutir os problemas da educação libertária no Brasil é algo bastante complexo, quer pela escassez de material a respeito do tema, quer pelo fato de que essa forma de educação nunca foi pública, no sentido de que tenha atendido a grandes parcelas da população, mas sempre esteve ligada ao aparelho sindical, comandado pelos anarquistas que eram constantemente perseguidos pelas forças repressivas do Estado brasileiro.

Para entender melhor esta discussão devemos levar em consideração o fato de que apesar de escolas públicas estatais existirem desde muito tempo, foi durante a década de 1920 que passou a existir também as escolas libertárias financiadas pelos próprios trabalhadores que as criavam e usufruíam delas. Este trabalho procura refletir sobre este paradigma educacional, buscando verificar se entre elas existem semelhanças e diferenças que possam fazer com que consideremos a existência de duas modalidades de ensino.

Apresentar-se-á, portanto, uma discussão sobre essas modalidades de ensino: educação pública estatal nos séculos XIX e XX e educação libertária (suas idéias diretrizes e sua aplicação na primeira metade do século XX) com o objetivo de compreender as escolas anarquistas e apontar suas principais semelhanças e diferenças com relação às escolas públicas estatais, quer na forma de organização/administração, quer nas metodologias e conteúdos aí trabalhados.

As leituras realizadas sobre o tema sugerem a existência de uma ampla área de pesquisa já que parece haver grandes diferenças entre estas modalidades de ensino e que precisam ser estudadas. As diferenças que observamos, aparecem desde a base da educação, dos princípios, do conceito de educação arraigado a cada uma das modalidades em discussão, ou seja, educação pública estatal, educação libertária e educação anarquista.

Num primeiro momento, buscaremos apresentar as principais iniciativas educacionais por parte do Estado no decorrer da história a título de contextualização histórica da educação pública estatal no Brasil desde o século XIX, passando pelo recente século XX bem como as diretrizes apontadas para o século XXI.

Para o desenvolvimento deste trabalho procuramos apresentar uma idéia geral do anarquismo enquanto organização política e social para que se compreenda a idéia motriz da educação libertária.

Por fim, procuramos destacar alguns pontos em que as modalidades de ensino expostas se aproximam além de se fazer uma breve discussão a partir do que foi estudado e a educação que vemos hoje em dia. Esperamos, portanto, que nesta fase os objetivos propostos para o trabalho sejam atingidos.

Sobre a literatura utilizada, foram selecionadas leituras que tratam da ideologia anarquista e da história da educação, em que são contempladas sua organização e desenvolvimento através dos tempos, sobretudo com relação a educação pública estatal. São livros e artigos que tratam de todo o período estudado, ou seja, tais literaturas foram produzidas ao longo dos anos e não representam o reflexo de apenas um período histórico.

A literatura que trata sobre o assunto no período, via de regra, busca elucidar as características de cada modalidade de ensino a ser tratada neste trabalho cabendo-nos traçar um paradigma comparativo entre elas.

Nesse sentido, entendemos que a reflexão acerca da educação brasileira ao se considerar as idéias da educação libertária e dos ideais anarquistas que, ao contrário do que muitos podem pensar, não remetia de forma alguma à idéia de desordem, podem contribuir para a compreensão de um rico período de debates sobre o ideário libertário e as lutas desenvolvidas pelos trabalhadores que buscavam a construção de uma sociedade igualitária naquele período.

Para a reflexão inicial acerca da educação pública estatal brasileira e, sem a pretensão de dar conta de toda a história da educação ou de resumir aqui a Educação 
Brasileira, destacaremos as principais medidas tomadas pelos dirigentes do Estado em benefício da educação escolar, para que possamos, mais a frente, analisar as possíveis semelhanças e diferenças entre a Educação Pública Estatal Brasileira e as iniciativas educacionais tomadas pelos anarquistas.

Podemos considerar que a história da educação do Brasil iniciou no momento em que os jesuítas chegaram ao país em 1549 e que tinha o apoio da Coroa portuguesa para a constituição do que Dermeval Saviani no artigo "O legado educacional do "longo século XX' brasileiro" chama de "educação pública religiosa” (SAVIANI, 2006b, p. 16).

Segundo Saviani, com a expulsão dos jesuítas em 1759 pelo Marquês de Pombal, foi determinado o fechamento dos colégios jesuítas e a introdução das "aulas régias" ainda mantidas pela Coroa (SAVIANI, 2006b, p. 16/17).

Saviani ainda coloca que

As reformas pombalinas contrapõem-se ao predomínio das idéias religiosas e, com base nas idéias laicas inspiradas no Iluminismo, instituem o privilégio do Estado em matéria de instrução, surgindo assim, a nossa versão da "educação pública estatal" (SAVIANI, 2006b, p. 17).

Entretanto, ainda de acordo com Dermeval Saviani, em outro artigo "O legado educacional do 'breve século XIX' brasileiro", a primeira iniciativa de uma educação pública estatal brasileira deu-se, inicialmente, com a independência do Brasil em 1822, dado que naquele momento

\begin{abstract}
impunha-se organizar como Estado a nova nação, o que implicava a promulgação de uma Constituição própria. Para tanto, foi convocada por decreto de Dom Pedro I, de 3 de junho de 1823, a Assembléia Nacional Constituinte e Legislativa. Em discurso na inauguração dos trabalhos da Assembléia, D. Pedro assinalou a necessidade de uma legislação especial sobre instrução pública (SAVIANI, 2006, p. 11).
\end{abstract}

Saviani afirma ainda que uma Comissão de Instrução pública foi formada e incumbida de promover "a organização de um sistema de escolas públicas, segundo um plano comum, a ser implantado em todo o território do novo Estado" (SAVIANI, 2006, p.12).

Mais tarde, após iniciativas como a das Escolas de Primeiras letras e o ato adicional de 1834, que transferia a responsabilidade dessas escolas para as províncias, com um ideário educacional ainda carregado das idéias iluministas, José Liberato Barroso, ministro do Império, publicou em 1867 um livro intitulado "A instrução pública no país" no qual sugeria a interferência do Estado no ensino e na instrução popular. E que sugeria um cenário educacional que ia contra as idéias liberais e afastava-se da Igreja considerando a educação dos dogmas retrógrada comparada ao status quo que se buscava manter (SAVIANI, 2006, p. 24 - grifo nosso).

Por fim, a direção tomada na última iniciativa política educacional do Império brasileiro, em 1879, foi a tentativa da implantação do método intuitivo dado que os teóricos criticavam a educação da época justificando que

forma alunos com domínio insuficiente de leitura e escrita e com noções de cálculo insatisfatórias, principalmente pelo fato de alicerçar a aprendizagem exclusivamente na memória, priorizar a abstração, valorizar a repetição em detrimento da compreensão e impor conteúdos sem exame e discussão (VALDEMARIN, 2006, p. 90). 
Os educadores do período criticavam a prática educativa até então desenvolvida, bem como as formas de instruir e, sugeriam o método intuitivo que visa o conhecimento das coisas a partir da experimentação, da vivência. Com isto, possibilitava-se a utilização de novos materiais como caixas (que funcionavam como "kits") para ensinar as cores, formas ou gravuras, estudos do meio, criação de museus pedagógicos, e objetos variados como linhas, aros e papéis que se afastavam cada vez mais dos antigos livros de memorização (VALDEMARIN, 2006, p. 91/92).

Com o início do regime Republicano as escolas ganham nova forma, inclusive porque, segundo Saviani, apesar das inúmeras iniciativas educacionais, não se podia falar em escola em termos de estrutura uma vez que os governos apenas normatizavam "pela via legal, os mecanismos de criação, organização e funcionamento de escolas que, por esse aspecto adquiriam o caráter de instrução pública. Mas, de fato, essas escolas continuavam funcionando em espaços privados, a saber, as próprias casas dos professores" (SAVIANI, 2006b, p. 17).

Também foi fator fundamental para a estruturação de escolas, a Reforma da Instrução Pública Paulista (que se estendeu à todos os estados) culminando com uma lei que previa, entre outros fatores, a criação de grupos escolares. A partir de então, nesse estado, passou a se colocar em um mesmo prédio várias turmas separadas por classes e séries, diminuindo assim, o número de classes multisseriadas.

Ainda Segundo Saviani, a graduação do ensino proposta pelos Grupos Escolares garantia uma "mais eficiente divisão do trabalho escolar, ao formar classes com alunos de mesmo nível de aprendizagem. E essa homogeneização do ensino possibilitava um melhor rendimento escolar". Entretanto,

em contrapartida, essa forma de educação conduzia, também, a mais refinados mecanismos de seleção, com altos padrões de exigência escolar, "determinando inúmeras e desnecessárias barreiras à continuidade do processo educativo", o que acarretava "o acentuado aumento da repetência nas primeiras séries do curso" (SAVIANI, 2006b, p. 30).

Porém, segundo Saviani, a graduação do ensino

trata-se, pois, de um modelo que se foi disseminando por todo o país, tendo conformado a organização pedagógica da escola elementar que se encontra em vigência, atualmente, nas quatro primeiras séries do ensino fundamental. Com certeza é esse o principal legado educacional que a fase inicial do "longo século XX" nos deixou. (SAVIANI, 2006b, p. 29).

Após a Primeira Guerra Mundial o analfabetismo no Brasil apresentava índices altíssimos levando ao surgimento de campanhas e frentes para "desenvolver o sistema escolar e democratizar o acesso ao ensino básico [...] num movimento carregado de idéias cívicas, patrióticas, nacionalistas, onde a questão da difusão da escola popular, a escola primária, aparecia de forma relevante" (GHIRALDELLI Jr., 1987, p. 25) originando um verdadeiro "entusiasmo pela educação" .

Segundo Paulo Ghiraldelli Jr., não houve intervenções práticas que alterassem o cenário, mas um "vigoroso movimento de idéias" que denunciava a realidade nada animadora de uma situação de insuficiência no ensino básico em todos os estados brasileiros.

Em 1919 a Liga Nacionalista do Brasil incluía em seus objetivos a difusão do ensino popular e, em 1924, com a penetração do imperialismo americano através de empréstimos públicos e instalações de empresas subsidiárias (como a General Motors) veio 
também o imperialismo cultural. Segundo Ghiraldelli Jr., "na educação as idéias da Pedagogia Nova, sob o regrário dos escritos de Dewey, Kilpatrick e outros, ganharam força nos anos 20, chegando a direcionar os intelectuais liberais" (GHIRALDELLI Jr., 1987, p. $30)$.

Assim, no final da década de 1920

a questão da alfabetização das massas parecia querer ceder um lugar para um movimento que considerava mais relevante a reestruturação interna das escolas, as mudanças dos conteúdos e métodos pedagógicos, a introdução de técnicas pedagógicas com a moderna psicologia (GHIRALDELLI Jr., 1987, p. 31).

Isso porque ainda segundo esse autor, durante a década de 1910, o "entusiasmo pela educação" caracterizava uma preocupação quantitativa com a educação. Já nos anos de 1920, com o "otimismo pedagógico", a preocupação com a educação passava a ser mais qualitativa.

Paulo Ghiraldelli Jr. ressalta ainda que

as teses inspiradas na Pedagogia Nova vinham mescladas com uma excessiva preocupação com as questões da higiene, da sexualidade, da saúde; além disso, também estavam presentes os tradicionais temas referentes à educação cívica, educação moral, patriotismo, etc. (GHIRALDELLI Jr., 1987, p. 34).

Em dezembro de 1931, segundo Saviani, durante a IV Conferência Nacional de educação, o chefe do governo provisório Getúlio Vargas "solicitou aos presentes que colaborassem na definição da política educacional do novo governo" (SAVIANI, 2006b, p. 34), o que além de tumultuar a Conferência, resultou na resposta em forma de manifesto em março de 1932. Era o Manifesto dos Pioneiros da Educação Nova, dirigido ao governo e à população e que

propunha-se a realizar a reconstrução social pela reconstrução educacional. Partindo do pressuposto de que a educação é uma função essencialmente pública, e baseado nos princípios da laicidade, gratuidade, obrigatoriedade, co-educação e unicidade da escola, o manifesto esboça as diretrizes de um sistema nacional de educação, abrangendo de forma articulada, os diferentes níveis de ensino, desde a educação infantil até a universidade (SAVIANI, 2006b, p. 33).

Tal iniciativa de incentivar a criação de um sistema nacional de ensino, segundo Saviani, influenciou inclusive a Constituição Federal de 1934 que em seu texto "deixa clara a exigência de se organizar a educação em âmbito nacional, já que estabelece a necessidade de diretrizes a serem observadas em todo o território do país" (SAVIANI, 2006b, p. 35). O autor ainda ressalta que essa exigência manteve-se na Constituição do Estado Novo em 1937.

Em 1946, a Reforma Capanema viria organizar o ensino seriado que se manteve, ainda que flexibilizado, segundo Saviani (2006b, p. 38), na lei de diretrizes e bases da Educação (LDB) de 20 de dezembro de 1961.

Depois deste período tivemos algumas iniciativas educacionais, de ampliação de vagas e reorganização do ensino, principalmente durante a ditadura militar, sobretudo através dos acordos MEC-USAID que, segundo Saviani, desencadearam "um processo de reorientação geral do ensino no país" (SAVIANI, 2006b, p. 41), tanto com a reforma da LDB através da lei de número 5.692 de 1971, que ampliou o ensino primário de quatro 
para oito anos como com a nova Constituição promulgada em 5 de outubro de 1988 que, ainda de acordo com Saviani, atendeu a várias reivindicações da comunidade educacional como o "direito à educação desde o zero ano de idade, a gratuidade do ensino público em todos os níveis, a gestão democrática da educação pública [etc]" (SAVIANI, 2006b, p. 46).

Saviani afirma ainda, que com a promulgação da Constituição e a atribuição à União de fixar as diretrizes e bases da educação nacional, "deu-se início ao processo de elaboração da nova LDB já em dezembro de 1988 [...] processo este que culminou na aprovação, em 20 de dezembro de 1996, da lei n. 9.394, que fixou as novas diretrizes e bases da educação nacional" (SAVIANI, 2006b, p. 46) em vigor.

Em 1997 foi publicado o documento, de ordem nacional, que fixa os "Parâmetros Curriculares Nacionais" (PCN's) que, segundo o próprio documento, foi elaborado após profunda análise da situação educacional no país. De tal análise surgiu uma proposta inicial que foi, amplamente discutida entre profissionais ligados à educação, inclusive representantes sindicais.

O documento demonstra que houve alguma evolução na discussão a respeito da totalidade da educação, ao definir um parâmetro nacional e de responsabilidade do Estado, bem como a preocupação com as peculiaridades regionais de um país com tamanha diversidade cultural como o nosso, passando a fazer parte dos objetivos da legislação educacional.

Outro fator importante presente no documento dos Parâmetros Curriculares Nacionais é a questão do ensino religioso que, segundo o documento:

Quanto ao ensino religioso, sem onerar as despesas públicas, a LDB manteve a orientação já adotada pela política educacional brasileira, ou seja, constitui disciplina dos horários normais das escolas públicas, mas é de matrícula facultativa, respeitadas as preferências manifestadas pelos alunos ou por seus responsáveis (art. 33) (BRASIL, 2007, p. 14).

Além disso, o documento coloca a importância da formação de cidadãos críticos, reflexivos e atuantes:

$\mathrm{Na}$ sociedade democrática, ao contrário do que ocorre nos regimes autoritários, o processo educacional não pode ser instrumento para a imposição, por parte do governo, de um projeto de sociedade e de nação. [...] Para isso faz-se necessária uma proposta educacional que tenha em vista a qualidade da formação a ser oferecida a todos os estudantes. $\mathrm{O}$ ensino de qualidade que a sociedade demanda atualmente expressa-se aqui como a possibilidade de o sistema educacional vir a propor uma prática educativa adequada às necessidades sociais, políticas, econômicas e culturais da realidade brasileira, que considere os interesses e as motivações dos alunos e garanta as aprendizagens essenciais para a formação de cidadãos autônomos, críticos e participativos, capazes de atuar com competência, dignidade e responsabilidade na sociedade em que vivem (BRASIL, 2007, p. 27).

Porém, não nos cabe neste trabalho, discutir se o texto dos Parâmetros Curriculares Nacionais retrata a realidade vivida no país.

Outro ponto a ser destacado nos PCN's é a importância da saúde e meio ambiente no processo educativo pela importância de tais temas na sociedade atual, pois de acordo com este documento

No contexto atual, a inserção no mundo do trabalho e do consumo, o cuidado com o próprio corpo e com a saúde, passando pela educação 
sexual, e a preservação do meio ambiente são temas que ganham um novo estatuto, num universo em que os referenciais tradicionais, a partir dos quais eram vistos como questões locais ou individuais, já não dão conta da dimensão nacional e até mesmo internacional que tais temas assumem, justificando, portanto, sua consideração (BRASIL, 2007, p. 27).

Entretanto, talvez o principal ponto abordado no texto introdutório dos PCN's seja o que trata da metodologia necessária à educação. Contrária ao ensino tradicional, onde o aluno é mero receptor do conhecimento produzido e o professor, em contrapartida, é mero transmissor, o texto propõe uma metodologia onde haja maior interação entre professor, aluno e conhecimento, e que de tal relação a aprendizagem origine-se através da experimentação, do convívio com o ambiente e com o outro:

Para tanto, é necessário que, no processo de ensino e aprendizagem, sejam exploradas: a aprendizagem de metodologias capazes de priorizar a construção de estratégias de verificação e comprovação de hipóteses na construção do conhecimento, a construção de argumentação capaz de controlar os resultados desse processo, o desenvolvimento do espírito crítico capaz de favorecer a criatividade, a compreensão dos limites e alcances lógicos das explicações propostas. Além disso, é necessário ter em conta uma dinâmica de ensino que favoreça não só o descobrimento das potencialidades do trabalho individual, mas também, e sobretudo, do trabalho coletivo. Isso implica o estímulo à autonomia do sujeito, desenvolvendo o sentimento de segurança em relação às suas próprias capacidades, interagindo de modo orgânico e integrado num trabalho de equipe e, portanto, sendo capaz de atuar em níveis de interlocução mais complexos e diferenciados (BRASIL, 2007, p. 28).

Outro documento bastante discutido no início deste século foi o relatório da UNESCO, publicado em 2000, cujo relator foi Jacques Dellors e a Comissão Internacional sobre educação para o século XXI.

Segundo o relatório, a aprendizagem dos instrumentos necessários à compreensão, ou o "aprender a conhecer"

visa não tanto a aquisição de um repertório de saberes codificados, mas antes o domínio dos próprios instrumentos do conhecimento pode ser considerado, simultaneamente, como um meio e como uma finalidade da vida humana. Meio, porque se pretende que cada um aprenda a compreender o mundo que o rodeia, (...) finalidade, porque seu fundamento é o prazer de compreender, de conhecer, de descobrir (DELORS, 2000, p. 90/91)

Essa concepção de construção do conhecimento através da experimentação, do contato com o mundo que nos rodeia, é a idéia diretriz da metodologia educacional que vemos tendo sua continuidade e crescimento (no que concerne à questão da aplicação) durante o início do século XXI que vivemos.

Neste documento, portanto, sob os termos "aprender a conviver" e "aprender a conhecer" encontramos a base metodológica das propostas contidas nos PCN's, derivando para o "aprender a aprender" (BRASIL, 2007, p. 28).

Ainda no ano de 2000, foi aprovado o Plano Nacional de Educação no qual o Congresso Nacional determina que os estados e municípios devem elaborar planos 
decenais correspondentes à modalidade de ensino pelo qual são responsáveis bem como a avaliação periódica da aplicação do Plano.

No que se refere às metas e objetivos do Ensino fundamental, o texto do Plano decenal é bem próximo ao dos Parâmetros Curriculares Nacionais, salvo uma modificação: "Ampliar para nove anos a duração do ensino fundamental obrigatório com início aos seis anos de idade, à medida que for sendo universalizado o atendimento na faixa de 7 a 14 anos" (BRASIL, 2007b, p. 24). A justificativa para tal alteração (explicada anteriormente no próprio documento) baseia-se no fato de que um aluno entrar na escola aos seis anos é "padrão na grande maioria dos sistemas, inclusive nos demais países da América Latina. Corrigir essa situação constitui prioridade da política educacional” (BRASIL, 2007b, p. 22).

Vemos, portanto, que a educação no Brasil sofreu importantes modificações no decorrer dos séculos desde a chegada dos jesuítas até o início do século XXI.

Entretanto, acreditamos que antes de pensarmos e analisarmos as iniciativas por parte dos anarquistas e, assim, buscarmos as semelhanças e diferenças, seria de fundamental importância que entendêssemos de uma forma geral as idéias do anarquismo enquanto organização política e social para que se compreenda mais tarde a idéia motriz da educação libertária.

Segundo o dicionário de Aurélio Buarque de Holanda Ferreira, "anarquia" significa: "1. Falta de governo ou de chefe; 2. Confusão e desordem disso resultante", já para "anarquismo", a definição é a que segue: "Teoria que considera a autoridade um mal e preconiza a substituição do Estado pela cooperação de grupos associados" (FERREIRA, 1993, p. 30).

Quanto à definição que remete a anarquia à "confusão" e "desordem" Caio Túlio Costa explica que "o anarquista, ao contrário do emérito destruidor, seria o regenerador que vai restabelecer o equilíbrio necessário à sociedade. Quem fala em equilíbrio não pensa em caos" (COSTA, 1990, p. 16).

Costa afirma ainda que, "anarquia" (do grego anarchos) "etimologicamente quer dizer sem governo, sem autoridade, sem superiores" (COSTA, 1990, p. 12). A abstenção do governo é explicada e/ou motivada pela idéia de "ação direta", um dos princípios geradores do anarquismo que, como destaca Silvio Gallo em seu artigo "Anarquismo e Filosofia da Educação" é formado por quatro "princípios básicos de teoria e ação": (a) autonomia individual - a dialética entre indivíduo e sociedade, onde esta só existe a partir do agrupamento de indivíduos e estes não existem fora da sociedade; (b) autogestão social - contrária à idéia de democracia representativa e propõe a democracia participativa onde há gestão direta da sociedade; (c) internacionalismo - revolução globalizada e não o isolamento de ações em cada país; (d) ação direta - massas construindo revoluções e gerindo o processo através de atividades que traduzem essa ação de forma direta (GALLO, 2008).

A ação direta implica no agir sem aceitar os princípios da representatividade (gestão representativa), mas atuar em conjunto, gerir diretamente as ações políticas através da autogestão (gestão participativa).

Outro fator característico dos anarquistas é a não aceitação da religião. Costa explica que esse ideal vem dos preceitos de Mikail Bakunin que "enlaça o conceito de Estado com o de Deus e os proclama como principais adversários da liberdade humana" (COSTA, 1990, p. 16). No Brasil, assim como em todo o mundo, a relação (e porque não dizer, a "parceria") do Estado com a Igreja é histórica e foi de grande preocupação dos anarquistas nas lutas que travaram. 
Tais lutas sempre foram em prol de melhorias nas condições de vida e trabalho dos imigrantes que trouxeram as primeiras idéias anarquistas. Essa chegada aconteceu em um momento em que a cultura do café se expandia frente à queda nas exportações de algodão e açúcar. Entretanto, até aquele momento, a mão de obra era predominantemente escrava mas, após 1850, com a criação de leis impeditivas do tráfico negreiro ficaram em número limitado para os grandes produtores como mão-de-obra disponível no país.

José Damiro de Moraes destaca que uma das primeiras medidas dos produtores na tentativa de acumular mão-de-obra foi a migração de "escravos saídos do nordeste, já decadente, para atender à falta de trabalhadores nas plantações de café localizadas em São Paulo e Rio de Janeiro, que se expandiam" (MORAES, 1999, p. 07).

Essa medida adotada não prosperou por elevar o valor dos escravos acima da capacidade de pagamento de alguns senhores, além de aumentar o custo da mão-de-obra. Ainda foi fator de impedimento a criação de uma lei que proibia esse tráfico interno de escravos. A abolição da escravatura encaminhava-se para a sua proclamação e os grandes produtores se viam na condição de remediá-la antes de sua concretização. A solução encontrada foi a da imigração européia.

$\mathrm{Na}$ bagagem dos imigrantes italianos e espanhóis ligados às lutas sociais européias que vieram "suprir as necessidades da expansão cafeeira e fornecer mão-de-obra para as indústrias que se desenvolviam nos centros urbanos" (MORAES, 1999, p.9) chegaram as idéias anarquistas.

No entanto, esse movimento precisava de um instrumento de propaganda e, não há dúvidas de que o maior instrumento utilizado para difundir o anarquismo eram seus jornais e periódicos. Os representantes do anarquismo procuravam a conscientização do povo através da imprensa que foi de grande valia para adesão de novos militantes, a comunicação entre eles e a divulgação dos ideais. Os jornais que mais se destacaram foram "A Voz do Trabalhador", "A Plebe" e "A Lanterna", entre outros.

Entretanto, o alto índice de analfabetismo entre os trabalhadores (que, segundo Ghiraldelli Jr. (1987, p.16) em 1890, quando o Brasil tinha 14 milhões de habitantes, chegava a $85 \%$ da população) dificultava essa comunicação, por isso, a questão educacional sempre esteve presente nos ideais dos anarquistas, mas no Brasil a educação estava nas mãos da Igreja, do Estado, e da iniciativa privada (em forma de escolas particulares e professores particulares que lecionavam nas casas dos filhos daqueles que compunham a elite) que eram inimigos declarados dos libertários.

Dessa forma, cabe ao aparelho estatal tomar as principais iniciativas com respeito a educação, sobretudo porque a escola pública estatal poderia servir para combater as idéias anarquistas e as libertárias. Idéias que passaremos a fazer uma breve exposição, mormente no que toca a educação libertária e suas idéias diretrizes para que possamos estabelecer os paradigmas de semelhanças e diferenças entre as modalidades de ensino apresentadas.

De acordo com os anarquistas, somente através da educação é que se poderia construir a sociedade futura que segundo seus ideais seria igualitária, para tanto, deveria haver superação de classes definidas a partir da autoridade, passando as relações a serem apoiadas no princípio de liberdade. Liberdade esta a ser atingida como um fim, nunca servindo como meio para se atingir os objetivos educacionais.

Foi, inicialmente, com o objetivo de aumentar a participação nas organizações sociais e sindicais e alfabetizar os trabalhadores que os libertários encetaram a criação de iniciativas educacionais como as escolas e os centros de cultura que serão discutidos mais adiante. 
Segundo Silvio Gallo "os esforços anarquistas nesta área [educacional] principiam com uma crítica à educação tradicional, oferecida pelo capitalismo, tanto em seu aparelho estatal de educação quanto nas instituições privadas - normalmente mantidas e geridas por ordens religiosas" (GALLO, 2008) estimulando assim a criação de iniciativas próprias de educação uma vez que os libertários enxergavam a Igreja como aliada do Estado na tarefa de sustentar e manter a burguesia.

Tal acusação sobre o caráter ideológico da educação oferecida busca "mostrar que as escolas dedicam-se a reproduzir a estrutura da sociedade de exploração e dominação" (GALLO, 2008 - grifo do autor) e acrescentaria exclusão, uma vez que o acesso a tal educação era limitado à elite.

Inicialmente, a imprensa foi utilizada como meio pedagógico proporcionando aos trabalhadores o contato com os textos escritos. Já como instrumento de comunicação, a imprensa anarquista ajudou na divulgação de eventos para a angariação de fundos para a construção de vários tipos de iniciativas educacionais, como por exemplo, as bibliotecas que, além de serem mantidas pelos próprios trabalhadores, funcionavam no período da noite para facilitar o acesso dos interessados.

Paulo Ghiraldelli Jr. nos conta que a iniciativa mais instintiva e produtiva foi a criação dos Centros de estudos sociais por todo o território nacional criados com o objetivo principal de congregar os trabalhadores para discutir as idéias anarquistas. Ainda segundo esse autor, tais centros eram criados de forma "rápida e não requeria grandes empreendimentos" (GHIRALDELLI Jr., 1987, p. 117) além de ter por método educativo o ensino mútuo onde todos ensinam e aprendem mutuamente, ou seja, os que estão mais adiantados na matéria auxiliam os iniciantes. Para o financiamento dos centros, assim como das demais iniciativas educacionais, buscava-se o apoio dos próprios militantes e trabalhadores que aderiam à causa e à realização de eventos para a angariação de fundos.

Outra iniciativa que teve grande repercussão no Brasil foi a das escolas libertárias. Foi com o fuzilamento de Francisco Ferrer (grande propulsor do ideário educacional anarquista do qual falaremos mais tarde) em 1909, que intensificaram-se as iniciativas e deu-se início a um movimento que tinha por objetivo criar escolas nos moldes das que Ferrer havia dirigido na Espanha dando assim prosseguimento à sua obra. Seus nomes também não mudariam: Escolas Modernas ${ }^{5}$ (GHIRALDELLI Jr. 1987, p.28).

O objetivo de tais escolas era formar pessoas que pudessem ajudar a construir uma sociedade igualitária segundo os preceitos libertários a partir das idéias diretrizes importadas de educadores libertários estrangeiros.

Segundo os teóricos da educação libertária, a metodologia adotada era a científica e racional onde o aluno é o principal agente de seu aprendizado e seu professor um facilitador que direciona o aprendiz a livrar-se de preconceitos e idealizações que não proporcionassem o saber, o pensar e principal e fundamentalmente, a emancipação.

Essa metodologia da educação que tem por objetivo a liberdade pode gerar certos equívocos. Qualquer um ao ler que o objetivo da educação anarquista é a liberdade, pode pensar numa educação onde, ao invés de liberdade, há libertinagem, uma instituição sem regras onde se faz o que bem entender sem que conseqüências sejam medidas. Entretanto, Silvio Gallo explica que a educação para os libertários deve ter a liberdade como fim, e não como meio. Nesse sentido, entende-se que a disciplina constitui-se em elemento fundamental para a aprendizagem.

Dessa forma, através da educação, busca-se a liberdade no processo de desestruturação da autoridade, contando para isso, com a conscientização dos alunos. Mesmo apelando para a consciência dos alunos, os libertários sabem que se não se colocar regras, estabelecer limites e se deixar que todos façam tudo o que quiserem, acaba-se por 
criar alguém que não poderia sequer viver na sociedade como é, quiçá modificá-la. Os alunos devem entender que a sociedade como está não permite a participação do povo excluindo-o da própria sociedade. É importante que entendam também, que cabe ao próprio povo a mudança, porém a educação que lhes é dada pelo estado, não permite a esse povo que se tome consciência da realidade.

Ao contrário, analisando-se as idéias que direcionaram a criação de tal educação e os escritos de intelectuais libertários acerca da educação, pode-se concluir que, na educação libertária, o aluno não só é agente de seu aprendizado como é agente participativo de todo o processo educativo. Pode-se inclusive aplicar isso a questões comuns a qualquer instituição de ensino, libertária ou não, como a construção das regras, organização de horários, distribuição de aulas, e outros fatores que caracterizam uma escola podendo ser decididos por todas as pessoas que a freqüentam (seja como aluno ou funcionário) em assembléias onde não há diferenciação de valores para os votos. Tratar as pessoas como iguais. É uma importante característica da educação libertária. Entretanto, tais ideais foram inicialmente apresentados por alguns importantes teóricos da educação libertária, que chegaram ao país, como dito anteriormente, pela bagagem de imigrantes europeus.

Segundo José Damiro de Moraes, as principais idéias que nortearam as iniciativas educacionais anarquistas no Brasil foras as de "Miguel Bakunin (1814-1876), Eliseè Reclus (1830-1905), Paul Robin (1837-1912) e Francisco Ferrer (1859-1909)" (MORAES, 1999. p. 18).

Miguel Bakunin, segundo Moraes, afirma que uma sociedade precisa ser igualitária econômica, política e socialmente partindo-se do fim da propriedade privada e inclusive, do direito à herança. Defensor ferrenho da educação integral e permeada pelo conceito de liberdade, esse autor atentava-se, entretanto, ao fato de que só a educação não transformaria a sociedade uma vez que os alunos ao saírem da escola deparar-se-iam com uma realidade cujos princípios seriam contrários aos adquiridos na escola e o sistema, por ser mais forte que o indivíduo não tardaria a dominá-lo e desmoralizá-lo (MORAES, 1999, p. 19/20).

Eliseè Reclus, também segundo Moraes, ressalta a importância da educação das crianças ao se pensar em revolução uma vez que é preciso educar as crianças para serem os homens que gostaríamos de ser. Quanto a educação livre, a principal preocupação de Reclus é quanto ao formato das escolas e liceus da época (e por que não pensar nos de hoje) que se assemelham aos presídios. Para ele, os homens deveriam se ocupar com a educação das crianças para aproveitar com eles a natureza e guiá-los no estudo das ciências, das artes e da vida (MORAES, 1999, p. 21/22).

Paul Robin vê a criança como o centro e o objetivo do processo educativo já que, na concepção desse autor, deve-se partir do indivíduo para a coletividade. Para ele a própria curiosidade da criança deve ser a metodologia do ensino e o educador como incentivador dessa curiosidade. Outro fator que, no ideal de Robin, deve ter especial atenção é a educação corporal e dos sentidos com o ensino de idiomas, e jogos que estimulem o tato, o olfato, o paladar e a audição (MORAES, 1999, p. 22/23).

Entretanto, como Francisco Ferrer y Guardía teve até prorrogação de sua obra no Brasil, nos ateremos mais a ele.

Ferrer y Guardía escreveu uma obra intitulada "La Escuela Moderna" indispensável para um amplo conhecimento da educação libertária. Nesse livro, o autor descreve inclusive o processo de idealização e fundação da Escola Moderna bem como seus preceitos e um pouco de seu desenvolvimento. 
Ferrer y Guardía, ao longo de sua obra, baseado nos preceitos libertários anteriores a ele, entende que a criança nasce sem idéia pré-concebida e constrói suas idéias a partir da convivência com as pessoas ao seu redor e as leituras que faz disso. Essa é a idéia diretriz do autor: a educação pela experiência, pela vivência, pelo contato com as coisas.

O objetivo, ou como o próprio Ferrer coloca, a missão da Escola Moderna era a formação completa e racional da criança enquanto indivíduo inserido na sociedade:

La misión de la Escuela Moderna consiste en hacer que los niños y niñas que se le confíen lleguen a ser personas instruidas, verídicas, justas y libres de todo prejuicio. Para ello, sustituirá el estudio dogmático por el razonado de las ciencias naturales. Excitará, desarrollará y dirigirá las aptitudes propias de cada alumno, a fin de que con la totalidad del propio valer individual no sólo sea un miembro útil a la sociedad, sino que, como consecuencia, eleve proporcionalmente el valor de la colectividad. Enseñará los verdaderos deberes sociales, de conformidad con la justa máxima: No hay deberes sin derechos; no hay derechos sin deberes (FERRER y Guardia, 2005, p. 07 - grifo do autor).

A obra de Ferrer y Guardía retrata uma profunda preocupação com fatores que estão presentes na convivência em sociedade e na vivência escolar como a desigualdade social, o ensino religioso, a co-educação dos sexos, o cuidado com a higiene e a presença das famílias na escola. Esse autor discute tais pontos como sendo fundamentais na educação em artigos publicados no "Boletim da Escola Moderna" (e posteriormente colocados no livro "La Escuela Moderna"), periódico destinado a noticiar os acontecimentos da instituição e dissertar acerca de assuntos ligados à educação proferida na escola.

A necessidade da co-educação de ambos os sexos foi justificada por Ferrer y Guardía a partir da situação da mulher na sociedade patriarcal. Segundo ele, embora durante a cerimônia do casamento se diga ao homem que a mulher é sua companheira, ela acaba por viver subjugada às ações do marido não podendo exercer ação benéfica para a sociedade. E, para que a mulher possa exercer tais ações, ela precisa ser educada, informada, tanto quanto os homens.

A questão da higiene é tratada a fim de conscientizar os alunos de que a sujeira pode trazer doenças além de um prejuízo de socialização uma vez que se repugna qualquer objeto, animal ou pessoa, suja. A importância dessa consciência, segundo o autor é a repercussão que se dá nas casas dos alunos que chegam a mudar a rotina da família. A higiene do ambiente escolar era fundamental para a conscientização dos alunos e é explicada como "proteção da escola" que "persigue um fin eminentemente social, la condición fundamental e indispensable para que la educación intelectual sea eficaz". (FERRER y Guardía, 2005, p. 22).

Quanto ao ensino religioso, Ferrer y Guardía explica que a contrariedade perante tal ensino se deve ao fato de que

la ciencia ha demostrado que la creación es uma leyenda y que los dioses son mitos, y por conseguiente se abusa de la ignorancia de los padres y de la credulidad de los niños, perpetuando la crencia en un ser sobrenatural, creador del mundo, y al que puede acudirse con ruegos y plegarias para alcanzar toda clase de favores (FERRER y Guardía, 2005, p. 42/43). 
Outro fator que vai contra o ensino religioso é a questão que diz respeito aos prêmios e castigos abominada pelos libertários e muito presente na religião como forma de garantia de boa conduta das pessoas.

Um último fator que se considera fundamental e, principalmente atual é a questão do multiculturalismo. Hoje muito se fala no tema, mas na concepção libertária a educação deve ser fundada "no princípio da igualdade natural dos homens, de que se deriva a exigência do desenvolvimento de todas as suas possibilidades e que pretende formar na criança uma personalidade equilibrada e afastada de todo preconceito e de todo dogmatismo" (BERNAL, 2006, p. 15).

Obviamente, o Estado espanhol e a Igreja não viam com bons olhos as iniciativas de Ferrer y Guardía, sendo inclusive preso acusado de iniciar um levante antimilitar do qual nem participou. Ferrer y Guardía foi fuzilado em 1909.

\section{Algumas considerações, ainda preliminares}

Considerando-se que, neste momento temos as iniciativas educacionais de ordem pública estatal e a idéia geral do anarquismo bem como suas idéias acerca da educação em geral e alguns apontamentos sobre sua breve atuação no Brasil, podemos pensar algumas possíveis semelhanças e diferenças entre tais modalidades de ensino que, ao primeiro olhar nos parecem providas de concepções completamente opostas. Entretanto, em certo ponto da história esses ideais se cruzam e podem parecer até mesmo semelhantes. Vejamos em que momentos tais ideais se aproximam e se afastam.

De acordo com Paulo Ghiraldelli Jr., com o fim do período Imperial, e com a modernização do país, discussões acerca da educação só fizeram crescer. Segundo ele, "A república recebeu, assim, uma herança consubstanciada num razoável 'fervor ideológico', onde as idéias de democracia, federação e educação apareceram como soluções indispensáveis no sentido de acompanhar a modernização do país" (GHIRALDELLI Jr., 1987, p.15).

Nos ideários anarquistas também vemos a grande preocupação com a educação onde ela aparece da mesma forma, como "solução indispensável" para a mudança no país. Entretanto, se analisarmos a importância dada à questão educacional no período republicano pelo Estado e pela vertente libertária, a intenção do primeiro, ao que parece, seria a de, através da educação, domar o povo para poder então buscar as ferramentas para a modernização do país que, quando conquistadas, só atenderiam aos interesses da elite.

Ao contrário, no ideário anarquista, a educação seria também uma ferramenta fundamental de modernização e crescimento do país, só que através da construção de uma sociedade igualitária. A educação para os anarquistas serviria para educar as crianças para, quando crescidos, romper com a sociedade dominante e, num ideal futuro, administrar a sociedade ideal, onde não haveria distinções de classe, sexo, raça, nem autoridade.

Inúmeras vezes, durante a história da educação brasileira, vimos a intervenção de alguns teóricos no sentido de propor um ensino mais igualitário. Entretanto, tais iniciativas nunca vão além das idéias. Um exemplo disso foi o breve ministério de Benjamin Constant em 1890 que além da divisão das escolas em níveis almejava, ao menos em seus discursos, um ensino "livre, leigo e gratuito". Porém, esse ministério durou apenas dois anos e não promoveu as mudanças que preconizou (GHIRALDELLI Jr., 1987, p. 18/19).

Podemos dizer que as questões educacionais no Brasil sofreram de um "desânimo" entre os anos de 1890 e 1915, onde as discussões acerca da educação diminuíram substancialmente por parte do Estado. Ao analisarmos, a cronologia das 
iniciativas acerca da educação no Brasil, vemos que por volta de 1890, durante o início da República, tivemos as iniciativas dos Grupos Escolares, depois somente em 1915 em meio a Primeira Guerra Mundial é que, segundo Ghiraldelli Jr., as campanhas e frentes para

desenvolver o sistema escolar e democratizar o acesso ao ensino básico (...) num movimento carregado de idéias cívicas, patrióticas, nacionalistas, onde a questão da difusão da escola popular, a escola primária, aparecia de forma relevante (GHIRALDELLI Jr., 1987, p. 25).

Durante esse espaço de tempo onde "arrefeceram-se os ânimos" refletindo "uma diminuição de tentativas de análise e de programação educacional" (GHIRALDELLI Jr., 1987, p. 19), vemos crescer as iniciativas anarquistas, principalmente a criação de escolas. Este fato indica que a ausência de iniciativas estatais favoreceu o crescimento e a repercussão das iniciativas educacionais anarquistas por conta de uma menor repressão por parte do Estado já que este estava com os ânimos arrefecidos com relação à educação.

Em 1895 começaram a surgir escolas libertárias pelo Brasil, a começar pelo Rio Grande do Sul com a "Escola União Operária". Vemos em seguida a expansão desse ideário no cenário educacional do país e, em 1919, logo que os ânimos em relação à educação começam a despontar, o fechamento das escolas modernas. Claro que as iniciativas anarquistas não existiram apenas nesse espaço de tempo de pouco ânimo, porém, após este período, sua presença não era mais tão intensa, por conta da repressão.

Entretanto, quando o país voltou a se encher de ânimo para a educação, começaram a surgir idéias que aparentemente aproximavam-se dos ideais libertários tão brutalmente interrompidos. É sobre isso que Paulo Ghiraldelli Jr., afirma que, durante as décadas de 1910 e 1920, enquanto o Brasil viveu a novidade da Pedagogia nova a qual serviu de base para que intelectuais das elites dirigentes voltassem seus olhares para a educação, ao apontar que

não está fora de propósito afirmar que o discurso das vanguardas libertárias refletia, em boa parte, as diretrizes do pensamento desenvolvido pelos intelectuais ligados às elites dirigentes (GHIRALDELLI Jr., 1987, p. 110/111).

Essa proximidade está nas teses expostas pela Pedagogia Nova que, segundo Ghiraldelli Jr., "vinham mescladas com uma excessiva preocupação com as questões da higiene, da sexualidade, da saúde" (GHIRALDELLI Jr., 1987, p.34). Preocupações estas que, como vimos, são expostas como fundamentais para a educação anarquista na obra de Ferrer y Guardía. Entretanto, continua Ghiraldelli Jr, "além disso, também estavam presentes os tradicionais temas referentes à educação cívica, educação moral, patriotismo, etc.” (GHIRALDELLI Jr., 1987, p.34). Já tais preocupações não são vistas com bons olhos por parte dos anarquistas.

Em 1932, mais uma vez vemos uma proximidade das idéias anarquistas com as propagadas em discursos dispostos a uma mudança no cenário educacional brasileiro. No Manifesto dos Pioneiros da Educação Nova buscava-se um sistema nacional de educação e a articulação entre os níveis de ensino "baseado nos princípios da laicidade, gratuidade, obrigatoriedade, co-educação e unicidade da escola" (SAVIANI, 2006b, p. 33).

Vemos novamente presentes temas considerados fundamentais na concepção educacional anarquista: laicidade, gratuidade, obrigatoriedade, co-educação e unicidade da escola. Entretanto, as mudanças efetivas demoraram a aparecer e quando o fizeram foi de forma lenta, um exemplo é o fato de a função de fixar as diretrizes e bases da educação só 
passar a ser de responsabilidade da União com a Constituição de 1946 e que ainda assim, só se concretizou com a Lei de Diretrizes e Bases da Educação de 1961.

Essa questão sobre a "responsabilidade de fixar diretrizes educacionais", poderíamos considerar como uma diferença quando comparada ao ideal anarquista. Isso porque como vimos, segundo os libertários, a educação deve ser feita pelas pessoas que usufruem dela. A gestão da educação deve ser participativa e não representativa por parte de um governo. A responsabilidade, portanto, deve ser de quem faz e de quem recebe educação.

No Brasil, a Lei de Diretrizes e Bases da educação passou por muitas mudanças e só em 1996, é que podemos dizer que se instituiu uma diretriz mais próxima dos ideais democráticos preconizados pelos defensores da educação libertária.

Podemos dizer que a educação proferida até então, era extremamente individual, livresca e com pouca relação com o real, além da quase ausência de estímulos a atividades em grupos ou contatos com materiais diversificados para uma aula. Com a aplicação dos PCN's, ao menos na intencionalidade proclamada, a educação sugerida aproximou-se dos ideários do aprender a aprender e do aprender em contato com o meio e com o outro, presente nas propostas libertárias. Alunos e profissionais da educação aprendem e ensinam dessa forma.

Podemos porém discutir a viabilidade da discussão em torno da aplicação desses documentos, garantidos em lei, que permitem uma visão diversificada da educação, e, como acreditava Ferrer y Guardía, obter melhores resultados, não apenas estatísticos, mas sobretudo, de caráter humano.

Diz-se isso por conta, exatamente das inúmeras "proximidades aparentes" entre as duas vertentes educacionais, como a valorização e o interesse pela educação em determinados tempos da história, o desligamento com a Igreja, e a proposta de um ensino mútuo em contato com o outro. Sempre que vemos certa proximidade com os ideais analisados, acabamos por constatar, no decorrer da história que mais tarde elas se afastam, ou pior, quando não são devidamente aplicadas pelas escolas, como por exemplo, os PCN's que, em muitos lugares não são seguidos, uma vez que, por serem "parâmetros", não são obrigatórios.

Vimos no decorrer desta pesquisa, episódios em que as semelhanças e diferenças ficam bem claras. Entretanto, a diferença fundamental entre a educação que vemos proferida pelas escolas brasileiras e as de cunho anarquista no início do século XX, sem dúvida, é a questão da representatividade, por parte do governo, na gestão educacional. E esta diferença, as torna completamente distantes, uma vez que a representatividade governamental na educação brasileira é a base da educação proferida.

O fundamental empecilho (apesar de não ser o único) para a fundação de uma Escola Moderna no Brasil hoje, é a questão financeira. A educação de hoje é regulada, dirigida e sustentada economicamente pelo Estado. Assim como fez Ferrer y Guardía, poderia-se muito bem organizar eventos para a angariação de fundos, mas é impossível pensar em uma escola que sobreviva somente de eventos, mesmo que esta seja a Escola Moderna.

Chega-se, portanto ao ponto fundamental da dificuldade em perpetuar as idéias libertárias no atual cenário educacional brasileiro. Entretanto, as iniciativas libertárias no que concerne assuntos educacionais, tem muito à acrescentar à prática de professores que estejam dispostos a diferenciar o ensino, a melhorar a educação proferida hoje, a elevar o nível de aprendizagem dos alunos e adquirir melhores resultados não apenas de cunho estatístico, mas resultados humanos que nos encheriam de orgulho. 


\section{Referências Bibliográficas}

BERNAL, A. O. Anarquismo espanhol e educação. In: EDUCAÇÃO LIBERTÁRIA Educação e Revolução na Espanha Libertária. nº 1 . $3^{\circ}$ quadrimestre de 2006. IEL. São Paulo: Imaginário. p.9-24.

BRASIL. Parâmetros Curriculares Nacionais. Documento Introdutório. 1997. In: http://portal.mec.gov.br/seb/arquivos/pdf/livro01.pdf . Consultado em 11/05/2007.

Plano Nacional de educação. Brasília, Câmara dos Deputados, 2000. In: http://portal.mec.gov.br/arquivos/pdf/pne.pdf . Consultado em 11/05/2007B.

COSTA, C. T. O que é anarquismo. $15^{\mathrm{a}}$ ed. Coleção Primeiros Passos. Ed. Brasiliense. 1990.

DELORS, J. Os quatro pilares da educação. In: Educação: um tesouro a descobrir. São Paulo: Cortez, Brasília, DF: UNESCO, 2000, p. 89-101.

FERREIRA, A. B. de H. Minidicionáro Aurélio da Língua Portuguesa. Ed. Nova Fronteira. Rio de Janeiro. 1993.

GALLO, S. Anarquismo e filosofia da educação. Disponível em: http://www.cedap.assis.unesp.br/cantolibertario/textos/0113.html. Consultado em 22/08/2008.

GHIRALDELLI Jr., P. Educação e movimento operário. São Paulo: Cortez: Autores Associados. 1987.

FERRER y Guardia, F. La Escuela Moderna. Disponível em: www.antorcha.net/biblioteca_virtual/pedagogia/escuelamoderna/indice.html. Consultado em 07/06/2005.

MORAES, J. D. de. A trajetória educacional anarquista na Primeira República: das escolas aos centros de cultura social. Dissertação de Mestrado. Universidade Estadual de Campinas. 1999.

SAVIANI, D. O legado educacional do "breve século XIX" brasileiro. In: SAVIANI, D. et al. O Legado Educacional do Século XIX. $2^{\mathrm{a} e d . ~ 2006 . ~ p . ~ 8-31 . ~}$

O legado educacional do "longo século XX" brasileiro. In: SAVIANI, D. et al. O Legado Educacional do Século XX no Brasil. 2aed. 2006b. p. 9-57.

VALDEMARIN, Vera Teresa. O método intuitivo: os sentidos como janelas e portas que se abrem para um mundo interpretado. In: SAVIANI, D. et al. O Legado Educacional do Século XIX. $2^{\text {a }}$ ed. 2006. p. 85-132. 


\section{Notas:}

1. Mestranda do Programa de Pós-Graduação em Educação da Universidade Federal de São Carlos (PPGE/UFSCar) - Área de concentração: Fundamentos da Educação.

2 . Professor do Departamento de Educação da Universidade Federal de São Carlos.

3. Termo cunhado por Jorge Nagle em: NAGLE. Jorge, Educação e Sociedade na Primeira República. $2^{\mathrm{a}}$ edição. DP\&A editora. 2001.

${ }^{4}$. Termo cunhado por Jorge Nagle em: NAGLE. Jorge, Educação e Sociedade na Primeira República. $2^{\mathrm{a}}$ edição. DP\&A editora. 2001.

${ }^{5}$ Fundadas em 13 de maio de 1912 depois de árdua arrecadação de fundos entre os trabalhadores, as primeiras duas unidades da Escola Moderna em São Paulo que tiveram como responsáveis João Penteado e Adelino de Pinho respectivamente às Escolas $n^{\circ} 1$ e n ${ }^{\circ} 2$, foram fechadas em 1919 por ordem do Diretor Geral da Instrução Pública de São Paulo sob a alegação de que as Escolas Modernas não cumpriam com as exigências de funcionamento após uma bomba ter explodido no bairro do Brás o que, segundo a justiça paulista teria sido um erro de cálculos por parte dos anarquistas. O professor João Penteado recorreu nas instâncias em que pôde mas foi vencido e as escolas fechadas.

Artigo recebido em: 08/10/2008

Aprovado para publicação em: 15/05/2009 